\title{
Women's values and preferences and health state valuations for thromboprophylaxis during pregnancy : A cross-sectional interview study
}

\section{Bates, Shannon M.}

2016-04

Bates , S M , Alonso-Coello , P , Tikkinen, K A O , Ebrahim , S , Lopes , L C , McDonald , S D , Zhou , Q, Akl , E A , Neumann , I, Jacobsen , A F , Zhang , Y, Santamara , A , Annichino-Bizzacchi , J M , Sandset, P M , Bitar , W , Eckman , M H \& Guyatt, G H 2016 , ' Women's values and preferences and health state valuations for thromboprophylaxis during pregnancy : A cross-sectional interview study ', Thrombosis Research , vol. 140 , pp. 22-29 . https://doi.org/10.1016/j.thromres.2015.12.015

http://hdl.handle.net/10138/223943

https://doi.org/10.1016/j.thromres.2015.12.015

publishedVersion

Downloaded from Helda, University of Helsinki institutional repository.

This is an electronic reprint of the original article.

This reprint may differ from the original in pagination and typographic detail.

Please cite the original version. 


\section{Women's values and preferences and health state valuations for thromboprophylaxis during pregnancy: A cross-sectional interview study}

Shannon M. Bates ${ }^{\text {a,b }}$, Pablo Alonso-Coello ${ }^{\text {c,d,* }}$, Kari A.O. Tikkinen ${ }^{\text {c,e }}$, Shanil Ebrahim ${ }^{\text {c,f,g,h }}$, Luciane Cruz Lopes ${ }^{\text {i }}$, Sarah D. McDonald ${ }^{j}$, Qi Zhou ${ }^{c}$, Elie A. Akl ${ }^{c, k, l}$, Ignacio Neumann ${ }^{c, m}$, Anne Flem Jacobsen ${ }^{\mathrm{n}}$, Yuqing Zhang ${ }^{\mathrm{c}}$, Amparo Santamaría ${ }^{\circ}$, Joyce Maria Annichino-Bizzacchi ${ }^{\mathrm{p}}$, Per Morten Sandset ${ }^{\mathrm{q}}$, Wael Bitar ${ }^{\mathrm{r}}$, Mark H. Eckman ${ }^{\text {s, Gordon H. Guyatt }}{ }^{\mathrm{a}, \mathrm{c}}$

a Department of Medicine, McMaster University, Hamilton, ON, Canada

${ }^{\mathrm{b}}$ Thrombosis and Atherosclerosis Research Institute, Hamilton, ON, Canada

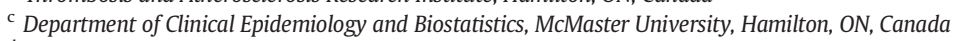

d Iberoamerican Cochrane Centre, CIBERESP-IIB Sant Pau, Barcelona, Spain

e Departments of Urology and Public Health, University of Helsinki and Helsinki University Hospital, Helsinki, Finland

${ }^{\mathrm{f}}$ Department of Anaesthesia, McMaster University, Hamilton, ON, Canada

${ }^{\mathrm{g}}$ Department of Medicine, Stanford University, Stanford, USA

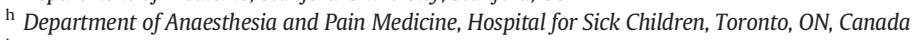

i Pharmaceutical Sciences, University of Sorocaba, UNISO, Sorocaba, Sao Paolo, Brazil

${ }^{j}$ Departments of Obstetrics \& Gynecology, Radiology, and Clinical Epidemiology and Biostatistics, McMaster University, Hamilton, ON, Canada

${ }^{\mathrm{k}}$ Department of Medicine, American University of Beirut, Beirut, Lebanon

${ }^{1}$ Department of Medicine, State University of New York at Buffalo, New York, NY, USA

${ }^{\mathrm{m}}$ Department of Internal Medicine, Pontificia Universidad Católica de Chile, Santiago, Chile

${ }^{n}$ Department of Obstetrics \& Gynecology, Oslo University Hospital and University of Oslo, Oslo, Norway

${ }^{\circ}$ Unidad de Hemostasia y Trombosis, Hospital de la Vall d'hebron Sant Pau, Barcelona, Spain

${ }^{\mathrm{p}}$ Hematology and Hemotherapy Center, Faculty of Medical Sciences, State University of Campinas, Campinas, SP, Brazil

${ }^{q}$ Department of Haematology, Oslo University Hospital and University of Oslo, Oslo, Norway

${ }^{\mathrm{r}}$ Brooks Memorial Hospital, Dunkirk, NY, USA

${ }^{\mathrm{s}}$ Division of General Internal Medicine and Center for Clinical Effectiveness, University of Cincinnati, USA

\section{A R T I C L E I N F O}

\section{Article history:}

Received 7 October 2015

Received in revised form 14 December 2015

Accepted 17 December 2015

Available online 22 December 2015

\section{Keywords:}

Women's health

Obstetrics and gynecology

Evidence-based medicine

Clinical practice guidelines

Decision making

\begin{abstract}
A B S T R A C T
Background: Pregnant women with prior venous thromboembolism (VTE) are at risk of recurrence. Prophylaxis with low molecular weight heparin (LWMH) reduces that risk but is inconvenient, costly, and may be associated with increased risks of obstetrical bleeding. The views of pregnant women, crucial when making prophylaxis recommendations, are currently unknown.

Methods: Cross-sectional international multicenter study. We included women with a history of VTE who were either pregnant or planning pregnancy. We provided information regarding risk of VTE recurrence with and without LMWH and determined participant's willingness to receive LMWH prophylaxis through direct choice exercises, preference-elicitation (utilities) for health states (e.g. burden of LMWH prophylaxis), and a probability trade-off exercise.

Results: Of 123 women, more women at high risk than those at low risk of recurrence ( $86.4 \%$ vs. $60.0 \% ; \mathrm{p}=0.003$ ) chose to use LMWH. The median threshold reduction in VTE at which women were willing to accept use of LMWH, given a 16\% risk of VTE without prophylaxis, was 3\% (interquartile range: 1 to 6). Participants' evaluation of the relevant health states varied widely and was unrelated to their direct choices to use or not use LMWH. Conclusions: Although the majority of women with a previous VTE, pregnant or planning pregnancy choose to take LMWH during pregnancy, a minority -and in low risk women, a large minority- do not. Our results highlight the need for individualized shared decision-making (SDM) in the clinical encounter, and for guideline panels to make weak recommendations in favor of LMWH that make clear the need for SDM.
\end{abstract}

(c) 2015 Elsevier Ltd. All rights reserved.

\footnotetext{
* Corresponding author at: Iberoamerican Cochrane Centre, CIBERESP-IIB Sant Pau, Barcelona, Spain.

E-mail addresses: batesm@mcmaster.ca (S.M. Bates), palonso@santpau.cat (P. Alonso-Coello), kari.tikkinen@gmail.com (K.A.O. Tikkinen), shanil.ebrahim@utoronto.ca (S. Ebrahim), luciane.lopes@prof.uniso.br (L.C. Lopes), mcdonals@mcmaster.ca (S.D. McDonald), qzhou@mcmaster.ca (Q. Zhou), ea32@aub.edu.lb (E.A. Akl), ignacio.neumann@gmail.com (I. Neumann), UXAFJA@ous-hf.no (A.F. Jacobsen), madisonz1220@gmail.com (Y. Zhang), parosanta@gmail.com (A. Santamaría), joyce@unicamp.br (J.M. Annichino-Bizzacchi), p.m.sandset@medisin.uio.no (P.M. Sandset), bitarwael@yahoo.com (W. Bitar), eckmanmh@ucmail.uc.edu (M.H. Eckman), guyatt@mcmaster.ca (G.H. Guyatt).
} 


\section{Introduction}

Pregnancy-associated venous thromboembolism (VTE), which may manifest as pulmonary embolism (PE) or deep vein thrombosis (DVT), is an important cause of maternal morbidity and mortality [1,2]. Women with prior VTE are at increased risk of thrombosis during subsequent pregnancies, although the absolute magnitude of that risk remains controversial $[1,3-5]$. Two randomized trials compared heparin prophylaxis to placebo or no prophylaxis in pregnant women with prior VTE but suffered from major limitations, including very small sample sizes [6,7]. Best estimates of the impact of prophylaxis to prevent recurrent pregnancy-related VTE, therefore, are based primarily on risk estimates from observational studies and indirect evidence from other settings suggesting that low molecular weight heparin (LMWH) decreases the risk of VTE by approximately $70 \%[1,8]$.

LMWH, which is recommended in this setting, does not cross the placenta, increase the risk of serious adverse fetal outcomes or significantly increase the risk of thrombocytopenia $(<0.1 \%)$ or osteoporosis $(<1 \%)$ [1]. It is, however, expensive, inconvenient, uncomfortable to administer, may be associated with an increased risk of major obstetrical bleeding $[1,9]$, and generally necessitates a planned delivery to permit epidural analgesia [1]. Additionally, women may perceive that LMWH creates an undesirable medicalization of their pregnancy.

Given the competing drawbacks and benefits of prophylaxis, as well as the limitations of the available evidence, the decision to use or not use LMWH is likely to be preference sensitive. In addition to holding different attitudes toward the risk of recurrent thrombosis and the burdens associated with the use of prophylaxis, women are also likely to place varying importance on seeing pregnancy as a normal part of a healthy woman's life, rather than as a medical condition. Although investigators have evaluated patients' values and preferences with respect to anticoagulant therapy in atrial fibrillation [10,11], and to a lesser extent in VTE [12]; a recent systematic review of patient preferences for antithrombotic treatment did not identify any studies addressing pregnant women [13]. We, therefore, addressed this gap in knowledge by determining the values and preferences, and the choices, of women with prior VTE who were currently pregnant or might in the future become pregnant.

\section{Materials and methods}

We summarize here the methods of our multi-center international cross-sectional interview study. Readers will find further details in a previously published protocol [14].

\subsection{Study population and eligibility criteria}

We included pregnant women with a history of lower extremity DVT or PE who were considering thromboprophylaxis to prevent recurrent antepartum VTE; women with a history of lower extremity DVT or PE who were planning pregnancy; and women 18 to 45 years of age with a history of lower extremity DVT or PE who might in the future become pregnant. We excluded women who were currently receiving thromboprophylaxis or full-dose anticoagulation, had undergone surgical sterilization (tubal ligation or hysterectomy), had a partner who had undergone a vasectomy, and those unwilling or unable to provide informed consent. The study was approved by the Ethics Committees at all participating institutions and all patients provided written informed consent.

\subsection{Recruitment strategy}

We prospectively identified women who were currently pregnant or planning a pregnancy as they were referred for counseling and identified women with a history of VTE with the potential to become pregnant by reviewing patient files. We approached women referred for consideration of thromboprophylaxis prior to their consultation and made initial contact with women who were not currently pregnant or planning a pregnancy by letter and then by telephone.

\subsection{Study maneuvers}

We used standardized scripts developed by the research team. Expert and non-expert clinicians and allied health professionals reviewed and revised the scripts to ensure clinical verisimilitude, as well as understandability and readability by a lay person with a grade 9 reading level. Scripts were translated, where necessary, using professional translators.

\subsection{The participant interview}

We collected information about the participants' age, highest educational level achieved and current pregnancy status; as well as details regarding their thromboembolic events (including occurrence of PE or DVT, number of events, date of the last event, presence or absence of precipitating factors prior to their event, known hypercoagulable states, family history of VTE, type and duration of treatment for their event(s), completeness of their recovery [presence or absence of residual chest pain or shortness of breath, and/or residual leg swelling, pain or discoloration]), and presence or absence of prior experience with injection of prophylactic doses of LMWH during pregnancy. Patients were classified as being at low or high risk for recurrent VTE during pregnancy based on precipitating factors associated with their initial event. Women were considered lower risk for antepartum recurrence if their previous event was associated with a major transient risk factor (leg casting, major surgery [spinal or general anesthetic for at least $30 \mathrm{~min}$ ], significant medical illness with hospitalization for at least three days, immobilization for at least three days, active malignancy) and they had no known thrombophilia. Women were considered higher risk if their event had been unprovoked, estrogen-related, or they were known to have a thrombophilia.

\subsection{Direct choice exercises}

We determined participants' willingness to receive LMWH prophylaxis through direct choice exercises using decision boards. Women initially completed what we refer to as the real-life scenario (representing the best estimate of their personal risk of recurrence), followed in order by hypothetical scenarios, the visual analog scale, the probability tradeoff exercise, a review of their answers, and finally questions to examine their understanding of the scenarios.

\subsubsection{Real-life scenario}

We initially presented women with a decision board that included the probabilities of developing VTE during pregnancy given the characteristics of their prior event. We constructed two boards, one for lower and one for higher risk of recurrence. Women at low risk were presented with a potential baseline risk of antepartum recurrence of 0 to $5 \%$ and high risk women with a baseline antepartum risk of 5 to $10 \%$. To ensure optimal understanding, the risk of recurrence with and without LMWH prophylaxis was presented in three different ways: table, bar chart and pictograph (Fig. 1).

For the VTE health state, we instructed women to consider their previous venous thromboembolic event. We instructed women with previous experience in the use of prophylactic LMWH for 2 weeks or longer during pregnancy to consider their previous experience when making a decision. We prepared a description of the experience of LMWH use throughout pregnancy for women without prior experience with LMWH prophylaxis during pregnancy (Appendix 1).

After they reviewed this information, participants decided whether or not they were willing to use LMWH during their current or future pregnancy. Following the interview, women referred for consideration of prophylaxis met with their health care provider and, if desired, 
discussed the information provided with family members, friends, or others.

\subsubsection{Hypothetical scenarios}

We provided study participants with three scenarios in which the baseline risk of recurrent VTE was varied (4\%,10\%, and 16\%). After interviewers showed each woman a decision board with pictograms, tables, and pictographs representing the three baseline risk levels and predicted risks with LMWH prophylaxis, participants expressed their willingness to use LMWH for each scenario.

\subsubsection{Probability trade-off}

Interviewers undertook probability trade-off exercises to determine participant thresholds for accepting LMWH prophylaxis. The interviewer systematically varied the risk of VTE with LMWH prophylaxis (alternating between high and low risks) to determine the minimum acceptable reduction in the risk of VTE with prophylaxis at which the participant would agree to initiate LMWH. We set this risk fixed at $16 \%$ (based on the upper bound of the $95 \%$ confidence interval around the risk of antepartum recurrence in the largest published prospective cohort [3]) on one side of the flipchart and offered probabilities ranging from 16 fewer VTE events per 100 pregnancies (maximum absolute risk reduction) to 0 less VTE events (same VTE risk as no prophylaxis) on the other side of the chart.

\subsection{Visual Analog Scale (feeling thermometer)}

We determined the value patients place on relevant health states (pregnancy with LMWH prophylaxis, pregnancy with their own most recent VTE experience, pregnancy-related DVT, pregnancy-related PE, and obstetrical bleed) using a visual analog scale called the Feeling Thermometer (FT) [14] (Appendix 2). When making ratings using the FT, women choose the score on the thermometer that represents the value they place on the health state they are evaluating. The FT is anchored at death (0) and full health (100).

\subsection{Check for consistency and understanding}

After presenting the descriptions and recording patient responses, interviewers reviewed participant responses to the various exercises to check for consistency in participants' choice. When interviewers identified inconsistencies, they offered participants a chance to review and change their responses, avoiding any suggestion that responses should be changed. The reasons for any apparent inconsistencies were determined and recorded. Following this consistency check, interviewers asked participants two standardized questions to evaluate their understanding of the information provided during the interview. Interviewers also provided a rating of the extent to which they believed the respondents had a clear understanding of the questions and their confidence in this assessment.

\subsubsection{Sample size}

Previous research from our group in patients with atrial fibrillation [10], and from other groups studying non-pregnant women with prior VTE [13], suggested that moderately precise estimates of patient preference can be obtained with sample sizes of approximately 100 participants. In the most relevant recent experience, co-investigators on the current project enrolled 96 patients with risk factors of atrial fibrillation [10]. This sample size provided an acceptable confidence interval around the primary outcome. Given the range of VTE prevented ( 0 to 16 ) in our study is smaller than the range for the primary outcome used in the atrial fibrillation study ( 0 to 100 ), we reasoned that we would find smaller variability and greater precision (smaller confidence intervals). We used the available resources to maximize the number actually recruited, which was 123.

\subsubsection{Analysis}

We calculated the median threshold reduction in VTE at which women were willing to accept use of LMWH and the interquartile range. We calculated the proportion of women who were willing to take prophylactic LMWH, in both real and hypothetical scenarios, and the associated 95\% confidence intervals (CI) in each of the low and high risk groups. For the different scenarios, we compared these proportions using a Chi-square test or Fisher's Exact test, depending on the event size. We calculated median and interquartile ranges of women's ratings for each health state due to the abnormal distribution of the data.

We developed multivariable linear regression models to explore determinants of the VTE threshold. In this analysis, the VTE threshold was the dependent variable. Independent variables included: i) previous experience of VTE categorized as severe (PE or previous DVT with residual symptoms) or non-severe (DVT without residual symptoms); ii) previous experience with prophylactic LMWH (yes, problematic; yes, no problems; no prior experience); iii) highest level of education completed (some postsecondary versus no postsecondary); iv) study site (North America, Northern Europe, Spain and Brazil); and vi) pregnancy status (currently pregnant or planning a pregnancy versus neither).

A planned analysis comparing results and the pattern of responses based on participant understanding of the study scenarios and questions was not undertaken as only 4 women were categorized as not understanding by the study interviewers.

\section{Results}

\subsection{Recruitment and characteristics of participants}

Between June 2011 and March 2013, we recruited 123 women (we approached 187 women, main reason [47 women] for not participating being women taking thromboprophylaxis or full dose anticoagulation) from seven centers in six countries (Canada, USA, Brazil, Finland, Norway and Spain), all of whom completed the interview. Table 1 presents women's characteristics, including location, education, and pregnancy status, previous VTE and LMWH experience, date of last event and risk of recurrence. Appendix 3 presents the proportion of VTE risk factors of recurrent VTE by strata (lower and higher risk women). Of note, 3 women were misclassified. Their results were analyzed as per their original study classification. The women were subsequently informed of the misclassification error and their true risk status.

\subsection{Probability trade-off}

The median threshold reduction in VTE risk at which women were willing to accept use of LMWH, given a fixed $16 \%$ risk of VTE without prophylaxis, was 3\% (interquartile range: $1 \%$ to $6 \%$ ). In our regression analysis, women with less than 2 weeks of previous experience with LMWH during pregnancy, compared to those with 2 weeks or more of previous experience required a greater VTE risk reduction $(2.0 \%$; 95\% CI: $0.3 \%$ to $3.8 \%$ ) (Table 2). Pregnant women and women planning pregnancy required a greater VTE risk reduction (1.6\%; $95 \% \mathrm{CI}:-0.0 \%$ to $3.3 \%$ ), compared to those neither pregnant nor planning a pregnancy, though the results did not reach conventional statistical significance $(p=0.07)$. No other factors were significantly associated with the VTE threshold.

\subsection{Real-life and hypothetical scenarios}

The majority of women were willing to use prophylactic LMWH in the real-life scenario ( 21 of 35 or $60.0 \%$ of low risk women and 76 of 88 or $86.4 \%$ of high risk women) ( $p$-value for difference between low 


\section{A) Example of Table Presenting the Risk of Antepartum VTE Recurrence for Women Considered at High Risk of Recurrent VTE during Pregnancy}

\begin{tabular}{|l|c|c|}
\hline & $\begin{array}{c}\text { Without low molecular weight } \\
\text { heparin use }\end{array}$ & $\begin{array}{l}\text { With low molecular weight heparin } \\
\text { use }\end{array}$ \\
\hline $\begin{array}{l}\text { Probability of developing a blood } \\
\text { clot during your pregnancy }\end{array}$ & $5-10$ in 100 & $1-3$ in 100 \\
\hline $\begin{array}{l}\text { Probability of NOT developing a } \\
\text { blood clot during pregnancy }\end{array}$ & $90-95$ in 100 & $97-99$ in 100 \\
\hline
\end{tabular}

Please take into account the burden of low molecular weight heparin during pregnancy B) Example of Bar Chart Presentation for Women Considered at Higher Risk of Recurrent VTE during
Pregnancy

\section{Without LMWH With LMWH}

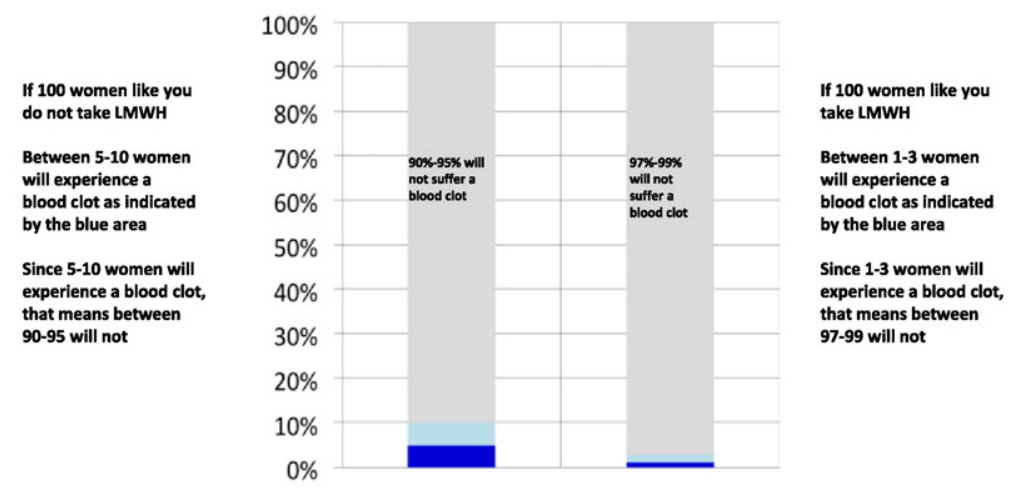

Please take into account the burden of low molecular weight heparin during pregnancy

C) Example of Pictograph Presentation for Women Considered at High Risk of Recurrent VTE during Pregnancy

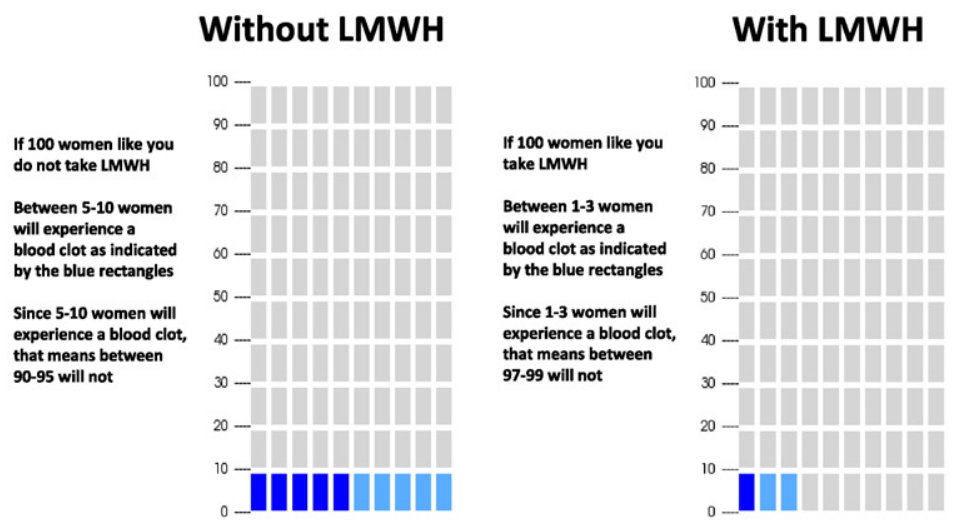

Please take into account the burden of low molecular weight heparin during pregnancy

Fig. 1. Examples of methods of presenting risk of antepartum VTE recurrence.

and high risk, 0.003). This proportion was smaller in the women pregnant or planning a pregnancy ( 26 of 36 or $76.2 \%$ at higher risk of recurrence and 11 of 20 or $55.0 \%$ of those at lower risk). The preference for prophylaxis was consistent in all three hypothetical (low, medium and high risk of VTE) scenarios $(67.0 \%, 84.0 \%, 89.7 \%$ respectively) (Table 3). 
Table 1

Baseline characteristics.

\begin{tabular}{|c|c|}
\hline Characteristic & \\
\hline Age (years; mean, SD) & $33.94(6.2)$ \\
\hline \multicolumn{2}{|l|}{ Region } \\
\hline North America (2 sites) & $53(43.1 \%)$ \\
\hline Spain (1 site) & $24(19.5 \%)$ \\
\hline Brazil (2 sites) & $33(26.8 \%)$ \\
\hline Northern Europe (2 sites) & $13(10.6 \%)$ \\
\hline \multicolumn{2}{|l|}{ Education level } \\
\hline Did not complete high school & $17(13.8 \%)$ \\
\hline Completed high school & $23(18.7 \%)$ \\
\hline Some postsecondary or higher & $83(67.5 \%)$ \\
\hline \multicolumn{2}{|l|}{ Pregnancy status } \\
\hline Pregnant \& Planning & $56(45.5 \%)$ \\
\hline Neither & $67(54.5 \%)$ \\
\hline \multicolumn{2}{|l|}{ Previous VTE experience } \\
\hline Severe (PE or DVT with residual symptoms) & $85(69.1 \%)$ \\
\hline Non-severe (DVT without residual symptoms) & $38(30.9 \%)$ \\
\hline \multicolumn{2}{|l|}{ Previous experience with LMWH } \\
\hline Use $>=2$ weeks during pregnancy & $31(25.2 \%)$ \\
\hline Never or $<2$ weeks & $92(74.8 \%)$ \\
\hline \multicolumn{2}{|l|}{ Date of last event } \\
\hline In the last year & $18(14.6 \%)$ \\
\hline 1 to 3 years ago & $35(28.4 \%)$ \\
\hline More than 3 years ago & $70(56.9 \%)$ \\
\hline \multicolumn{2}{|l|}{ Risk of recurrence } \\
\hline High & $88(71.5 \%)$ \\
\hline Low & $35(28.5 \%)$ \\
\hline
\end{tabular}

VTE: venous thromboembolism, PE: pulmonary embolism, DVT: deep venous thrombosis. Low risk of recurrence: prior VTE associated with a major transient risk factor within 8 weeks prior to event (i.e. leg casting, major surgery [spinal or general anesthetic 30 min], significant medical illness with hospitalization for $\geq 3$ days, immobilization for $\geq 3$ days, active malignancy) and no known thrombophilia.

High risk of recurrence: prior unprovoked VTE or VTE associated with minor transient risk factor within 8 weeks prior to event (i.e. pregnancy, hormonal contraception).

\subsection{Feeling thermometer}

The value placed on the scale ranging from 0 (death) to 100 (full health) was 83 (IQR $=70$ to 90 ) for pregnancy with LMWH prophylaxis and 30 (IQR = 15 to 50) for both pregnancy-related PE and for obstetrical bleeding (Table 4). Pregnancy with the participant's own most recent VTE experience and pregnancy-related DVT had values of 45 and 46 , respectively. We observed wide variability in the distribution of women ratings for the different health states. None of the health states utility ratings were significantly correlated with the VTE threshold.

\section{Discussion}

\subsection{Main results}

Our study shows that the majority of women with a previous VTE, regardless of pregnancy status or VTE risk, chose to take LMWH during pregnancy. The proportion of women choosing prophylaxis in the high risk group (almost 90\%) was significantly greater than in the lower risk group (60\%). The inclination to use LMWH at particular levels of benefit was greater in those without prior experience of LMWH compared to those with such experience. Participants' evaluations of the relevant health states varied widely and were unrelated to the direct choices to use or not use LMWH.

\subsection{Strengths and limitations}

Strengths of our study include the diversity of populations that included six countries in Europe and the Americas, and the rigorous study design documented in a previously published protocol [14]. That design included a structured interview with a predesigned script that
Table 2

Determinants of the VTE threshold as determined in the probability trade-off exercise using multivariable linear regression.

\begin{tabular}{|c|c|c|c|}
\hline Variables studied & $\begin{array}{l}\text { Coefficient }(95 \% \mathrm{CI}) \text {, } \\
\text { least squares means }\end{array}$ & $\mathrm{p}$ value & $\begin{array}{l}\text { Overall } \\
\text { p-value }\end{array}$ \\
\hline \multicolumn{4}{|l|}{ Region } \\
\hline Spain (1 site) & $-2.86(-4.92,-0.81), 1.44$ & 0.007 & \\
\hline Brazil (2 sites) & $-0.41(-2.53,1.70), 3.89$ & 0.70 & 0.07 \\
\hline Northern Europe (2 sites) & $-0.57(-3.21,2.06), 3.73$ & 0.67 & \\
\hline North America (2 sites) & Ref, 4.30 & & \\
\hline \multicolumn{4}{|l|}{ Pregnancy status (q12_2a) } \\
\hline Pregnant \& planning (56) & $1.56(-0.11,3.24), 4.12$ & 0.07 & / \\
\hline Neither (67) & Ref, 2.56 & & \\
\hline \multicolumn{4}{|l|}{ Previous VTE experience } \\
\hline $\begin{array}{l}\text { Severe (PE or DVT with } \\
\text { residual symptoms) (85) }\end{array}$ & $0.23(-1.47,1.92), 3.45$ & 0.79 & / \\
\hline $\begin{array}{l}\text { Non-severe (DVT without } \\
\text { residual symptoms) (38) }\end{array}$ & Ref, 3.22 & & \\
\hline \multicolumn{4}{|l|}{ Previous experience with LMWH } \\
\hline $\begin{array}{l}\text { Never or }<2 \text { weeks during } \\
\text { pregnancy }(92)\end{array}$ & 2.07 (0.30 3.85), 4.38 & 0.02 & / \\
\hline $\begin{array}{l}\text { Use }>=2 \text { weeks during } \\
\text { pregnancy }(31)\end{array}$ & Ref, 2.31 & & \\
\hline \multicolumn{4}{|l|}{ Education level } \\
\hline Completed high school (23) & $0.34(-2.26,2.97), 2.23$ & 0.24 & 0.75 \\
\hline $\begin{array}{l}\text { Some postsecondary or } \\
\text { higher }(83)\end{array}$ & $1.04(-1.56,3.64) .3 .92$ & 0.69 & \\
\hline $\begin{array}{l}\text { Didn't complete high school } \\
\text { (17) }\end{array}$ & Ref, 2.88 & & \\
\hline
\end{tabular}

was first pilot tested. Interviewers were trained and calibrated. The interview included the presentation of results in multiple ways to maximize understanding and the conduct of tests for understanding confirmed that almost all women understood our questions.

Our study has limitations. It may have been preferable to include only those women who were pregnant or planning pregnancy and to exclude those who might become pregnant in the future; the latter group constituted $50 \%$ of our sample. Results suggested that those who were referred for counseling due to pregnancy or planned pregnancy required a greater VTE reduction to use LMWH, although the results did not reach statistical significance; our overall results may therefore, represent an overestimate of women's inclination to use LMWH.

A second limitation relates to the number of variables that could be explored in our linear regression model that was limited by the number

Table 3

Willingness to take LMWH in real and hypothetical scenarios.

\begin{tabular}{|c|c|c|c|}
\hline & \multicolumn{2}{|c|}{ Risk of recurrence } & \multirow{2}{*}{$\begin{array}{l}\mathrm{p} \\
\text { value }\end{array}$} \\
\hline & $\begin{array}{l}\text { High } \\
(\mathrm{n}=88)\end{array}$ & $\begin{array}{l}\text { Low } \\
(\mathrm{n}=35)\end{array}$ & \\
\hline \multicolumn{4}{|l|}{ Real scenario } \\
\hline Yes & $76(86.36 \%)$ & $21(60.00 \%)$ & 0.003 \\
\hline No & $12(13.64 \%)$ & $13(37.14 \%)$ & \\
\hline Unsure & $0(0 \%)$ & $1(2.86 \%)$ & \\
\hline $\begin{array}{l}\text { Hypothetical scenario } \\
\text { (low; baseline risk of recurrence }=4 \% \text { ) }\end{array}$ & & & 0.46 \\
\hline Yes & $59(67.05 \%)$ & $21(60.00 \%)$ & \\
\hline No & $29(32.95 \%)$ & $14(40.00 \%)$ & \\
\hline $\begin{array}{l}\text { Hypothetical scenario } \\
\quad(\text { medium; baseline risk of recurrence }=10 \%)\end{array}$ & & & 0.05 \\
\hline Yes & $74(84.09 \%)$ & $24(68.57 \%)$ & \\
\hline No & $14(15.91 \%)$ & $11(31.43 \%)$ & \\
\hline $\begin{array}{l}\text { Hypothetical scenario } \\
\quad(\text { high; baseline risk of recurrence }=16 \%)\end{array}$ & & & 0.29 \\
\hline Yes & $79(89.77 \%)$ & $29(82.86 \%)$ & \\
\hline No & $9(10.23 \%)$ & $6(17.14 \%)$ & \\
\hline
\end{tabular}


Table 4

Health states ratings with the feeling thermometer.

\begin{tabular}{ll}
\hline Health state & Median (IQR) \\
\hline Pregnancy with LMWH prophylaxis & $83(70-90)$ \\
$\quad$ Using the standard description or previous experience (for those & \\
$\quad$ with two weeks or more of prophylactic LMWH during pregnancy) & \\
Pregnancy with their own most recent VTE experience & $45(30-60)$ \\
Pregnancy-related DVT & $46(30-65)$ \\
Pregnancy-related PE & $30(15-50)$ \\
Obstetrical bleed & $30(15-50)$ \\
\hline
\end{tabular}

$\mathrm{IQR}=$ Interquartile range.

of events. We chose to explore those we felt most likely to impact on women's choices. It is possible, however, that factors we failed to measure, including time elapsed from the last VTE event, and family history of VTE, may have also influenced decisions. In particular attitudes toward taking risks, might have been even more strongly associated with choice than those we measured and included in our analysis.

Thirdly, we chose to focus on the antepartum period. We could also have addressed another related, but fundamentally different choice: the choice regarding postpartum prophylaxis. Differences regarding that choice include different risks of thrombosis and bleeding, different duration of thromboprophylaxis, and the ability to use oral anticoagulants (vitamin $\mathrm{K}$ dependent antagonists) in those averse to subcutaneous injections and the shorter required timeframe for prophylaxis. A separate study would be required to delineate values and preferences around postpartum prophylaxis.

\subsection{Our study in relation to previous research}

Ours is the first study addressing values and preferences regarding VTE prophylaxis in pregnant women. As in previous studies [10,11, 13], we have observed that there is wide variability in patients' values and preferences and that, as a result, patients presented with identical probabilities of the same desirable and undesirable consequences will make different choices.

\subsection{Implications for practice and research}

Our results have implications for guideline panels, clinicians and patients. The most recent American College of Chest Physicians (ACCP) guidelines make weak recommendations in favor of antepartum LMWH for pregnant women at higher risk of recurrent VTE and against antepartum prophylaxis in those at low risk [1]. However, as the majority of well-informed women in both low and high risk groups in our study chose to use LMWH, guideline panel recommendations should probably favor LMWH prophylaxis in all women with prior VTE. That said, over $10 \%$ of women at high risk and close to half of those at low risk declined LMWH. Thus, for clinicians, our results demonstrate that ensuring each patient receives optimal management for her particular values and preferences will require individualized shared decision making. Guideline panel recommendations should be weak, reflecting this need for shared decision making.

Our results demonstrate the power of inquiry regarding values and preferences to determine both optimal approaches to individual decision-making and for informing guideline panel recommendations. There remains a paucity of information available informing patient values and preferences; much remains to be done. Researchers may find that our methods provide a helpful model for similar future studies.

\section{Financial support}

This study was funded by the Physicians' Services Incorporated (PSI) Foundation. Additional support for this study came from the Pfizer
Educational group, the Informed Medical Decisions Foundation, and NIH/NCATS Grant Number 8UL1TR000077-05. The funding sources had no role in study design, data collection, data analysis, data interpretation, or writing of this manuscript.

\section{Competing interests}

SMB has support from Physicians Services Incorporated Foundation and ME has support from NIH/NCATS Grant Number 8UL1TR00007705, the Pfizer Education Group, and Informed Medical Decision Foundation for the submitted work. KT was supported by the Academy of Finland (\#276046), Competitive Research Funding of the Helsinki and Uusimaa Hospital District, Finnish Medical Foundation, Finnish Cultural Foundation, Jane and Aatos Erkko Foundation, and Sigrid Juselius Foundation. SMB, PAC, KAOT, SE, LCL, SDM, QZ, EAA, IN, AFJ, YZ, AS, JMA-B, PMS, WB, MHE, GHG have no relations with companies that might have an interest in the submitted work in the previous 3 years. SMB, PAC, KAOT, SE, LCL, SDM, QZ, EAA, IN, AFJ, YZ, AS, JMA-B, PMS, WB, MHE, GHG have no non-financial interests that may be relevant to the submitted work.

\section{Contributors}

SMB, PAC, KAOT, SE, LCL, SDM, IN, QZ, ME, GHG designed the study. SMB, PAC, KAOT, LCL, EA, AFJ, AS, JM A-B, PMS, and WB enrolled patients. SMB, PAC, QZ, ME, and GHG analyzed the data. All of the authors participated in writing and reviewing the manuscript and agreed to submit this article for publication. All of the authors had full access to all of the data and can take full responsibility for the integrity of the data and the accuracy of the data analysis.

\section{Data sharing}

No additional data available.

\section{Acknowledgments}

SMB holds the Eli Lilly Canada/May Cohen Chair in Women's Health at McMaster University. PAC is funded by a Miguel Servet contract by the Instituto de Salud Carlos III (CP09/00137). KAOT was supported by unrestricted grants from the Finnish Medical Foundation and the Finnish Cultural Institution and receives ongoing funding from the Academic of Finland (\#276046), Jane and Aatos Erkko Foundation, and Sigrid Juselius Founction. SE was supported by a Canadian Institutes of Health Research (CIHR) Doctoral Award and currently supported by MITACS and SickKids RestracompPostdoctoral Awards P. LCL received support from FAPEST (Number of Process: 2013/051658). SDM is supported by a CIHR New Investigator Salary Award. The authors wish to acknowledge local clinicians and study nurses for enrolling patients and to thank all of the study participants. We are also thankful to Marta Gorgues and Andrea Cervera for their help with the preparation and submission of this manuscript.

\section{Appendix A}

Appendix 1

Description of low molecular weight heparin use during pregnancy provided to study participants.

\footnotetext{
Things to know about taking low molecular weight heparin to prevent blood clots during pregnancy

Preventative blood - You use low molecular weight heparin needles beneath thinning the skin for the rest of your pregnancy.

- You or a family member learn to give these needles.

- You continue blood thinners for at least 6 weeks after your baby is born, either with needles or with a tablet. If you
} 
Appendix 1 (continued)

Things to know about taking low molecular weight heparin to prevent blood clots during pregnancy

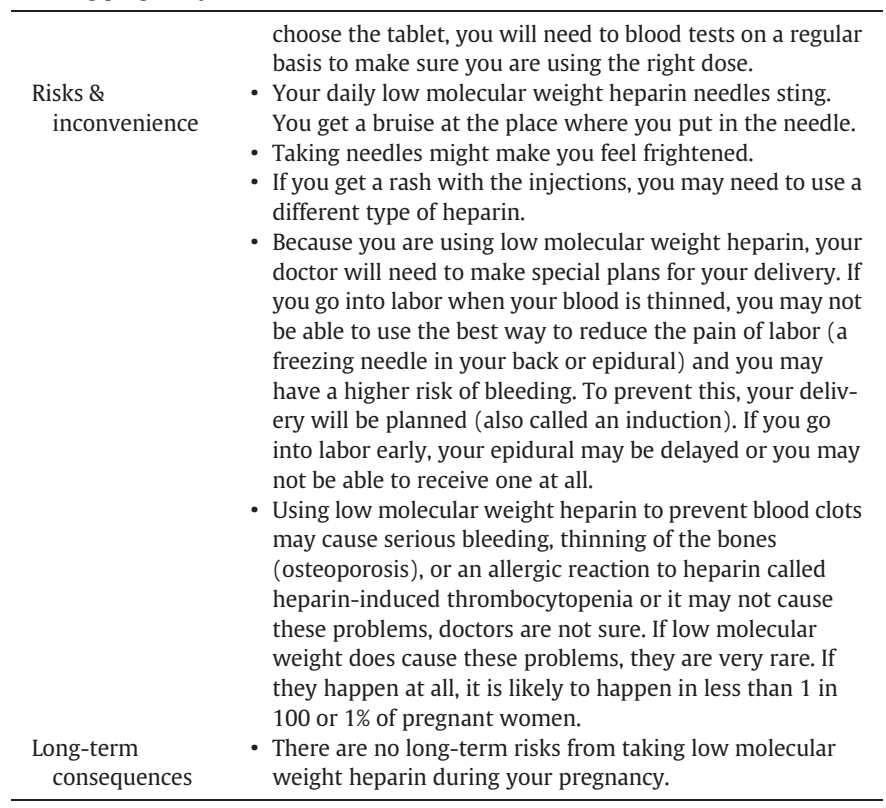

\section{Appendix 2}

Standardized health states.

\begin{tabular}{ll}
\hline Pregnancy-associated deep vein thrombosis \\
\hline $\begin{array}{l}\text { Symptoms \& } \\
\text { signs }\end{array}$ & Your leg is painful and swollen and hurts when you walk for \\
Treatment & more than short distances. \\
& Your doctor performs an ultrasound and confirms that you \\
& have a blood clot in your leg vein. You are admitted to the \\
- You worry about the health effects this blood clot might & have on your unborn baby \\
- You are treated with daily anticoagulant injections given \\
beneath your skin. You or a family member is taught to \\
administer these injections.
\end{tabular}

- Blood thinning therapy continues for a minimum of the length of your pregnancy and for 6 weeks afterwards.

- After delivery you might be treated with the same injection or switched to a tablet that requires you to travel for regular blood tests.

Risks - The daily injections sting and are associated with some bruising

- Skin reactions (e.g., itching or an itchy raised rash) can occur which may require switching to a different heparin preparation.

- Despite reassurance you are concerned that these medications may not be safe for your baby.

- You are told that there may be a small increase in the risk of major bleeding, osteoporosis (thinning of the bones), and having an allergic reaction to heparin called heparin-induced thrombocytopenia.

- Your delivery plans will need to be modified to allow you to receive an epidural, to minimize your risk of bleeding and to minimize the risk of additional blood clots. You may have an induced delivery.

Long-term - Your baby is not affected by your blood clot or blood thinconsequences ning medicine.

- Your leg returns to normal. After anticoagulants are stopped, you feel worried sometimes if you have aches or pains in your leg.

- You are at higher risk of blood clots in the future (your risk is perhaps 3 to $5 \%$ in the first year after stopping treatment; lower after that).

- You are asked if you would like testing for a clotting disorder.

- You are told you may be required to take blood thinning injections during future pregnancies.
Appendix 2 (continued)

Pregnancy-associated pulmonary embolism

Symptoms \& - For the past 3 days you are short of breath while sitting and signs unable to climb stairs or walk outside of your home without resting.

- You have moderate pain in your chest when you take a breath.

- You feel very worried about your health and your baby.

Treatment - Your doctor performs a test that involves exposure to a small amount of radiation that carries minimal risks to you and your baby and you are diagnosed with a blood clot in your lungs. You are admitted to hospital for several days.

- You worry about the health effects this test and your blood clot might have on your unborn baby.

- You are treated initially with intravenous blood thinners and then with daily anticoagulant injections given beneath your skin for the remainder of your pregnancy. You or a family member are taught to administer these injections.

- Blood thinning therapy continues for a minimum of the length of your pregnancy and for 6 weeks afterwards.

- After delivery you might be treated with the same injection or switched to a tablet that requires you to travel for regular blood tests.

Risks - The daily injections sting and are associated with some bruising.

- Despite reassurance you are concerned that these medications may not be safe for your baby.

- You are told that there may be a small increase in the risk of major bleeding, osteoporosis (thinning of the bones), and having an allergic reaction to heparin called heparin-induced thrombocytopenia.

- Your delivery plans will need to be modified to allow you to receive an epidural, to minimize your risk of bleeding and to minimize the risk of additional blood clots. You have an induced delivery.

Long-term - Your baby is not affected by your blood clot or blood thinconsequences ning medicines.

- Your breathing returns to normal but after blood thinners are stopped, you feel worried sometimes if you have chest discomfort or shortness of breath.

- You are at higher risk of blood clots in the future (your risk is perhaps 3 to $5 \%$ in the first year after stopping treatment lower after that).

- You are asked if you would like testing for a clotting disorder.

- You are told you may be required to take blood thinning injections during future pregnancies.

Major antepartum obstetrical bleed

\begin{tabular}{|c|c|}
\hline $\begin{array}{l}\text { Symptoms \& } \\
\text { signs }\end{array}$ & $\begin{array}{l}\text { - You develop abdominal pain, contractions and vaginal } \\
\text { bleeding in the later part of your pregnancy. }\end{array}$ \\
\hline Treatment & $\begin{array}{l}\text { - You are admitted to hospital. } \\
\text { - Intravenous lines are placed and you are given fluids. } \\
\text { - Your blood thinners are stopped. } \\
\text { - You require blood tests. } \\
\text { - An ultrasound is performed to assess your baby. } \\
\text { - Your baby's heart rate will be monitored. } \\
\text { - You remain in hospital for several days until your doctors } \\
\text { are sure that. Your bleeding has slowed or stopped. } \\
\text { - You and your baby will be closely monitored after } \\
\text { discharge. }\end{array}$ \\
\hline Recovery & $\begin{array}{l}\text { - You are worried about your baby's health. } \\
\text { - You may deliver early and may be more likely to need a } \\
\text { cesarean section. }\end{array}$ \\
\hline $\begin{array}{l}\text { Long-term } \\
\text { consequences }\end{array}$ & $\begin{array}{l}\text { - Your baby is okay. } \\
\text { - You feel worried with future pregnancies. } \\
\text { - You are at risk of placental abruption with future } \\
\text { pregnancies. } \\
\text { - Management of future pregnancies will be modified - you } \\
\text { will need to be more closely monitored than with a } \\
\text { routine pregnancy. }\end{array}$ \\
\hline
\end{tabular}


Appendix 3

Presence or absence of precipitating risk factors. ${ }^{\mathrm{a}}$

\begin{tabular}{|c|c|c|c|}
\hline $\begin{array}{l}\text { Risk factors occurring in the eight weeks } \\
\text { prior to the VTE diagnosis }\end{array}$ & $\begin{array}{l}\text { High risk } \\
\text { women } \\
(n=88)\end{array}$ & $\begin{array}{l}\text { Low risk } \\
\text { women } \\
(n=35)\end{array}$ & p-value \\
\hline \multicolumn{4}{|l|}{ Major risk factors } \\
\hline Leg casting & $1(1.14 \%)$ & $10(28.6 \%)$ & $<0.0001$ \\
\hline Major surgery & $3(3.4 \%)$ & $10(28.6 \%)$ & $<0.0001$ \\
\hline $\begin{array}{l}\text { Acute medical illness with hospital } \\
\text { admission for } \geq 3 \text { days) (Admission) }\end{array}$ & $3(3.4 \%)$ & $10(28.6 \%)$ & $<0.0001$ \\
\hline Immobilization $\geq 3$ days & $4(4.6 \%)$ & $18(51.4 \%)$ & $<0.0001$ \\
\hline Active cancer & 0 & $1(2.9 \%)$ & 0.28 \\
\hline \multicolumn{4}{|l|}{ Minor risk factors } \\
\hline Pregnancy & $18(20.5 \%)$ & $3(8.6 \%)$ & 0.18 \\
\hline Postpartum & $10(11.4 \%)$ & $5(14.3 \%)$ & 0.66 \\
\hline Hormonal contraception & $53(60.2 \%)$ & $17(48.6 \%)$ & 0.31 \\
\hline Airplane travel $>6 \mathrm{~h}$ & $5(5.7 \%)$ & 0 & 0.32 \\
\hline Known thrombophilia & $33(37.5 \%)$ & $1(2.9 \%)$ & $<0.0001$ \\
\hline
\end{tabular}

a Results add up to more than 100 because women could have more than one risk factor; patients with both major and minor risk factors at the time of the diagnosis were considered lower risk for recurrence. As noted in the text, 3 women were misclassified.

\section{References}

[1] S.M. Bates, I.A. Greer, S. Middeldorp, D.L. Veenstra, A.M. Prabulos, P.O. Vandvik, VTE thrombophilia, antithrombotic therapy, and pregnancy: antithrombotic therapy and prevention of thrombosis, 9th ed: American college of chest physicians evidencebased clinical practice guidelines, Chest 141 (2012) 3691S-3736S http://www. ncbi.nlm.nih.gov/pubmed/22315276.

[2] Centre for Maternal and Child Enquiries (CMACE). Saving Mothers' Lives: reviewing maternal deaths to make motherhood safer: 2006-08. The Eighth Report on Confidential Enquiries into Maternal Deaths in the United Kingdom. BJOG 2011; 118 (Suppl. 1): 1-203.

[3] P. Brill Edwards, J.S. Ginsberg, M. Gent, J. Hirsh, R. Burrows, C. Kearon, W. Geerts, M. Kovacs, J.I. Weitz, K.S. Robinson, R. Whittom, G. Couture, Safety of withholding heparin in pregnant women with a history of venous thromboembolism, N. Engl. J. Med. 353 (2000) 1439-1444.
4] De Stefano V, Martinelli I, rossi E, Battaglioli T, Za T, Mannuccio Mannucci P, Leone G. The risk of recurrent venous thromboembolism in pregnancy and puerperium without antithrombotic prophylaxis. Br. J. Haematol. 2006; 135: 386-391.

[5] I. Pabinger, H. Grafenhofer, A. Kaider, P.A. Kyrle, P. Quehenberger, C. Mannhalter, K. Lechner, Risk of pregnancy-associated recurrent venous thromboembolism in women with a history of venous thrombosis, J. Thromb. Haemost. 3 (5) (2005) 949-954.

[6] Gates S, Brocklehurst P, Ayers S, Bowler U. Thromboprophylaxis and pregnancy: two randomized controlled pilot trials that used low molecular weight heparin. Am J Obstet Gynecol 2004; 191: 1296-1303.

[7] R. Howell, J. Fidler, E. Letsky, M. de Swiet, The risks of antenatal subcutaneous heparin prophylaxis: a controlled trial, Br. J. Obstet. Gynaecol. 90 (1983) 1124-1128.

[8] R.D. Hull, G.F. Pineo, P.D. Stein, A.F. Mah, S.M. MacIsaac, O.E. Dahl, M. Butcher, R.F. Brant, W.A. Ghali, D. Bergqvist, G.E. Raskob, Extended out-of-hospital lowmolecular-weight heparin prophylaxis against deep venous thrombosis in patients after elective hip arthroplasty: a systematic review, Ann. Intern. Med. 135 (2001) 858-869.

[9] I.A. Greer, C. Nelson-Piercy, Low molecular weight heparins for thromboprophylaxis and treatment of venous thromboembolism in pregnancy: a systematic review of safety and efficacy, Blood 106 (2005) 401-407.

[10] P. Alonso-Coello, V.M. Montori, G. Diaz, P.J. Devereaux, G. Mas, A.I. Diez, Values and preferences for oral anti-thrombotic therapy in patients with atrial fibrillation: physician and patient perspectives, Health Expect. (2014 May 12)http://dx.doi.org/10. 1111/hex.12201.

[11] P.J. Devereaux, D.R. Anderson, M.J. Gardner, W. Putnam, G.J. Flowerdew, B.F. Brownell, S. Nagpal, J.L. Cox, Differences between perspectives of physicians and patients on anticoagulation in patients with atrial fibrillation: observational study, BMJ 323 (2001) 1218-1222.

[12] M. Locadia, P.M. Bossuyt, P.F. Stalmeier, J.A.G. Sprangers, C.J.J. van Dongen, S. Middeldrop, I. Bank, J. van der Meer, K. Hamulyak, M.H. Prins, et al., Treatment of venous thromboembolism with vitamin K antagonists: patients' health state valuations and treatment preferences, Thromb. Haemost. 926 (2004) 1336-1341.

[13] S. MacLean, S. Mulla, E.A. Akl, M. Jankowski, P.O. Vandvik, S. Ebrahim, S. McLeod, N. Bhatnagar, G.H. Guyatt, Patient Values and Preferences in Decision Making for Antithrombotic Therapy - A Systematic Review: Antithrombotic Therapy and Prevention of Thrombosis, 9th ed: American College of Chest Physicians Evidence-Based Clinical Practice Guidelines, Chest 141 (2_Suppl.) (2012) e1S-e23S, http://dx.doi.org/10. 1378/chest.11-2290.

[14] Alonso-Coello P, Ebrahim S, Guyatt GH, Tikkinen KA, Eckman MH, Neumann I, McDonald SD, Akl EA, Bates SM. Evaluating patient values and preferences for thromboprophylaxis decision making during pregnancy: a study protocol. BMC Pregnancy Childbirth 2012 May 30; 12:40. 